\title{
Power, policy ideas and paternalism in non-communicable disease prevention
}

\section{Oliver Bartlett*}

\begin{abstract}
Non-communicable disease prevention is shaped in large part by the ability of political actors to manipulate policy ideas. Actors that acquire sufficient policy-making power - usually through building social legitimacy - can work to ensure that certain ideas become influential in the policy-making process, thus making it more likely that their own interests are reflected in policy outcomes. This paper will argue that private actors, specifically multinational corporations, have been effective in achieving this to the extent that non-communicable disease policy has become dominated by ideas that are likely to lead to ineffective outcomes, thus reflecting private interests. It is therefore argued that efforts are needed to shift the balance of policy-making power back towards public interests. This would, it is argued, lead to an increase in regulation that could be accused of being paternalist - an eventually that can however be justified both ethically and legally.
\end{abstract}

\section{1 | INTRODUCTION}

Policy-making is guided by the interaction of ideas and interests. In the field of non-communicable disease prevention, this mixing of ideas and interests is especially complex, and policy outcomes are often heavily influenced by the balance of power within the process.

The concept of power in policy-making processes has been studied extensively. Power can be understood as the 'ability of a political actor to influence the behaviour of others in such a way as to gain a preferred outcome. ${ }^{1}$ It is also recognised that 'when several persons or organisations are involved in decision-making, mutual dependencies and the distribution of power or authority among the participants become important dimensions that characterise the process. ${ }^{2}$

In this paper I will investigate the acquisition of power in non-communicable disease (NCD) prevention policymaking. I will argue that private interests have been able to gain policy power through building perceptions of social legitimacy, and have used this power to promote the dominance of policy ideas that have led to the creation of

* Lecturer in Law, Liverpool School of Law and Social Justice.

${ }^{1}$ R.A. Hays, Federal Government and Urban Housing (State University of New York, 3rd edn, 2012), at 1.

${ }^{2}$ L. Kørnøv and W. Thissen, 'Rationality in Decision- and Policy-Making: Implications for Strategic Environmental Assessment' (2000) 18 Impact Assessment and Project Appraisal, 191-200, at 194.

This is an open access article under the terms of the Creative Commons Attribution License, which permits use, distribution and reproduction in any medium, provided the original work is properly cited.

(C) 2018 The Authors. European Law Journal Published by John Wiley \& Sons Ltd. 
several weak NCD prevention interventions. I argue that to restore full effectiveness to the policy-making process, different policy ideas must gain traction, and for this to be possible the policy power of private interests must be weakened. I further argue that, should this be achieved, the result is likely to be more regulation that could be considered paternalistic, yet that such a development is justifiable.

\section{I HOW DOES THE CURRENT ALLOCATION OF POLICY POWER LEAD TO INEFFECTIVE POLICY OUTPUTS?}

In this first section I argue that private interests have been able to seize power in NCD policy-making, and have used this power to bring about the dominance of ideas in the policy-making process that have prompted weak policy outputs. These interests are primarily multinational corporations that market alcohol, tobacco and unhealthy foods, the consumption of which are risk factors for NCD development. I will first outline what it means to have power in the policy-making process and how power is generated. I will then analyse how the exercise of power by private interests has led to the rise of policy ideas that direct policy-makers towards ineffective NCD prevention actions.

\section{1 | Policy interests and acquiring policy-making power}

The neo-pluralist theory of power best describes how power is distributed in NCD policy-making. This theory recognises that 'multiple pressure groups operate within society ... [yet] the agenda is, or is in danger of becoming, biased towards specific individuals and groups. ${ }^{3}$ Drawing on network theories of governance, which suggest that decisions on how to manage issues can be taken by a variety of different stakeholders with a common interest, rather than simply by governments, neo-pluralism posits that the irreversible process of globalisation means 'important decisions for societies are taken within transnational economic and political networks rather than by national or local institutions of representation. ${ }^{4}$ Actors with sufficiently high levels of resources (financial or otherwise) who operate within those networks are able to command great influence over crucial pressure points within globalised society-for instance, multinational corporations of sufficient size to have dominance in the global consumer products market-thereby accruing power within the transnational policy-making space.

As noted above, power can be understood as the 'ability of a political actor to influence the behaviour of others in such a way as to gain a preferred outcome. ${ }^{5}$ The fact that the exercise of power is an ability means it must be possible to acquire power. ${ }^{6}$ If it is possible to acquire power, there is therefore a process through which this is accomplished.

One candidate for such a process could be the practice of building perceptions of social legitimacy. ${ }^{7}$ As Buse and Harmer point out, the possession of innate authority and the strength to act upon it-such as that afforded to governments by their citizens through democratic elections-does not automatically generate true power for actors. Instead, it is the existence of a perception that strength has been used in line with authority and in a socially legitimate way that gives an actor power. ${ }^{8}$ Thus, as Barnett and Finnemore note, a government 'is powerful and commands

${ }^{3}$ K. Buse and A. Harmer, 'Power to the Partners? The Politics of Public-Private Health Partnerships' (2004) 47 Development, 49-56, at 51.

${ }^{4}$ S. Moutsios, 'Power, Politics and Transnational Policy-Making in Education' (2010) 8 Globalisation, Societies and Education, 121-141, at 135.

${ }^{5}$ Hays, Federal Government and Urban Housing, above, n. 1, at 1.

${ }^{6}$ See P.A. Hall, 'Policy Paradigms, Social Learning, and the State: The Case of Economic Policymaking in Britain' (1993) 25 Comparative Politics, 275-296, at 290.

${ }^{7}$ Buse and Harmer, 'Power to the Partners?', above, n. 3, at 53.

${ }^{8} \mathrm{lbid}$. 
deference, not in its own right, but because of the values it claims to embody and the people it claims to serve." Thus, legitimacy is the crucial link 'positioned between power and authority.' ${ }^{10}$

If acquiring power is process of building social legitimacy, then it follows that more than one political actor could achieve this, whether governmental or non-governmental. The interconnectedness of strength, authority, legitimacy and power means that if an actor has to translate its authority into power by legitimising its strength, it is logical to suggest that an actor who possesses strength can work to build an image of social legitimacy, and from this build a base of authority (instead of being given it by the democratic process), and consequently gain power.

In the field of NCD policy, multinational corporations (MNCs) that produce alcohol, tobacco and unhealthy foods have managed to acquire power in exactly the above manner. MNCs are in a position of strength due to their command of the market, ${ }^{11}$ and, by portraying themselves as 'serv[ing] some valued and legitimate social purpose', ${ }^{12}$ they have managed to secure a platform as authoritative stakeholders on NCD issues, which they have exploited to accrue and exert power on the policy process in order to influence its direction. The more they influence the policy process, the more power becomes concentrated in their hands.

MNCs have acquired the legitimacy and authority needed to exercise policy-making power by manipulating the political landscape of NCD policy, including the actors that operate within it.

Politics and policy-making are very different spheres of action. Politics describes 'the participation of citizens in public activities aimed at dialogue, critique, and deliberation on existing or new policies. ${ }^{13}$ It identifies the process of deciding who has the authority to govern and the discussion that takes place within government or between government and citizens. Conversely, policy-making refers to 'the sum total of government action, from signals of intent to the final outcomes. ${ }^{14}$ It is conducted by 'authorised decision-makers and specialised expertise [and] is thus a hierarchical and instrumental process ... [which] sets an agenda, determines goals, uses data, chooses courses of implementation, evaluates results and modifies initial goals. ${ }^{15}$ Therefore the difference between politics and policy-making is that politics is the channel through which problems such as NCDs are discussed and the authority to deal with these problems is apportioned, and policy-making is the process through which these problems are acted upon. Consequently, it if an actor wishes to exert control in a particular policy-making field, they must first control the politics of that field.

MNCs in positions of market dominance (and therefore strength) have used a number of tactics to manipulate the politics of NCD prevention so as to portray themselves and their views as socially legitimate, in order to gain authority and therefore power in the policy-making process. First, MNCs have exploited the extremely sensitive nature of NCD prevention in order to put across populist views in a far more forceful way than any other group, to ensure that information which mostly supports their own position tends to circulate with the greatest prominence whenever NCDs are discussed. ${ }^{16}$ Second, MNCs have managed to portray themselves as an acceptable and normal part of society. Using marketing, MNCs have managed to 'mask [the] uncomfortable truths [about themselves and their products] by disguising inanimate corporate monoliths as benign friends under the guise of branding, ${ }^{17}$ creating an environment where they and the products they sell are perfectly ordinary and commonplace, and even a valued part of many people's lives. Third, MNCs have managed to turn attention away from their own

\footnotetext{
${ }^{9}$ M. Barnet and M. Finnemore, Rules for the World: International Organizations in Global Politics (Cornell University Press, 2004$)$, at 21.

${ }^{10}$ Buse and Harmer, 'Power to the Partners?', above, n. 3, at 53.

${ }^{11}$ See D.H. Jernigan, 'The Global Alcohol Industry: An Overview' (2009) 104(Suppl. 1) Addiction, 6-12.

${ }^{12}$ Barnett and Finnemore, Rules for the World, above, n. 9, at 21.

${ }^{13}$ Moutsios, 'Power, Politics and Transnational Policy-Making', above, n. 4, at 123.

${ }^{14}$ P. Cairney, Understanding Public Policy: Theories and Issues (Palgrave Macmillan, 2011), at 5.

${ }^{15}$ See Moutsios, above, n. 4, at 124.

${ }^{16}$ See R. Jahiel and T. Babor, 'Industrial Epidemic, Public Health Advocacy and the Alcohol Industry: Lessons from Other Fields' (2007) 102 Addiction, 1335-1339, at 1336.

${ }^{17}$ G. Hastings, 'Why Corporate Power Is a Public Health Priority' (2012) 345 British Medical Journal, e5124.
} 
activities and towards those of the individual. By focusing on delivering a rhetoric of personal responsibility to portray the burden as being firmly upon individuals to look after their own health, ${ }^{18}$ and by conducting numerous corporate social responsibility exercises to portray industry operators as helpful partners to governments and individuals, ${ }^{19}$ MNCs present themselves as 'part of the solution rather than the problem'. ${ }^{20}$

These tactics to manipulate the political landscape of NCD prevention have been successful to the extent that governments often recognise MNCs as legitimate voices in the debate, and have conferred a certain amount of extra authority upon them (in addition to the social authority they have built). This has been both informal and formal: informally through the formation of links between MNCs and politicians which then constitute subtle pressure points through which MNCs can exert their influence; ${ }^{21}$ and formally through giving MNCs a place at the policy-making table itself, as has occurred in the UK's Responsibility Deal, ${ }^{22}$ and in the EU's Alcohol and Health Forum and Platform on Diet, Physical Activity and Health. ${ }^{23}$

Consequently, through the building of legitimacy, MNCs have managed to manipulate the political process such that politicians have conferred authority upon them, and this authority, combined with their perceived legitimacy and existing strength, gives them the ability to exert real power in the policy-making process. MNCs have exercised this power unhesitatingly through direct and indirect channels to further manipulate policy-making in order to promote their preferred policy outcomes. It is to the manipulation of the policy-making process that the next section of this paper turns.

\subsection{Policy ideas and the exercise of policy power to promote ineffective interventions}

MNCs would of course prefer for no regulatory interference at all to be made with their practices. However, most MNCs would also prefer to avoid open warfare in the policy-making process and potentially endanger their aura of legitimacy by becoming labelled as a 'demon industry'-as has already happened to some extent with tobacco producers. ${ }^{24}$ Therefore in most circumstances, the wider interests of MNCs, and fiduciary duties to shareholders, ${ }^{25}$ are best served through pursuit of the 'goal of influencing policy options in an industry-friendly but less effective direction'. ${ }^{26}$ MNCs will participate in an apparently cooperative manner in policy-making, yet seek to influence policy development towards 'smokescreen' policies-those with high visibility but low evidential impact upon consumption levels. ${ }^{27}$

The most obvious candidates for smokescreen interventions are measures based on information provision. These are highly visible-mostly comprising public awareness campaigns and labelling that is designed to be

${ }^{18}$ D. Thomson, 'Big Food and the Body Politics of Personal Responsibility' (2009) 74 Southern Communication Journal, 2-17.

${ }^{19} \mathrm{~S}$. Yoon and T. Lam, 'The Illusion of Righteousness: Corporate Social Responsibility Practices of the Alcohol Industry' (2013) 13 BMC Public Health, 630.

${ }^{20}$ Hastings, 'Why Corporate Power Is a Public Health Priority', above, n. 17.

${ }^{21}$ For example, MNCs offer lucrative employment opportunities to politicians after they leave office, in return for favours while in office. On this and other lobbying tactics, see W. Wiist, 'Lobbying, the Revolving Door, and Campaign Contributions: The Center for Responsive Politics' in W. Wiist (ed.), The Bottom Line or Public Health (Oxford University Press, 2010), at 139.

${ }^{22}$ A. Gilmore, E. Savell and J. Collin, 'Public Health, Corporations and the New Responsibility Deal: Promoting Partnerships with Vectors of Disease?', (2011) 33 Journal of Public Health, 2-4.

${ }^{23}$ See O. Bartlett and A. Garde, 'The EU Platform and EU Forum: New Modes of Governance or a Smokescreen for the Promotion of Conflicts of Interest?' in A. Alemanno and A. Garde, Regulating Lifestyle Risks: The EU, Alcohol, Tobacco and Unhealthy Diets (Cambridge University Press, 2015), at 283.

${ }^{24}$ T. Oliver, 'The Politics of Public Health Policy' (2006) 27 Annual Review of Public Health, 195-233, at 200.

${ }^{25}$ Hastings, 'Why Corporate Power Is a Public Health Priority', above, n. 17.

${ }^{26}$ S. Casswell, 'Vested Interests in Addiction Research and Policy: Why Do We Not See the Corporate Interests of the Alcohol Industry as Clearly as We See Those of the Tobacco Industry?' (2013) 108 Addiction, 680-685, at 681.

${ }^{27}$ See Bartlett and Garde, 'The EU Platform and EU Forum', above, n. 23. 
noticed-however, there is little evidence that these strategies actually work. ${ }^{28}$ This is usually attributed to the fact that consumers are presumed to be economically rational information processors by policy-makers, ${ }^{29}$ yet in fact possess 'finite limits to absorb and process information during any given unit of time,', ${ }^{30}$ operate within bounded rationality, ${ }^{31}$ and use decision-making short-cuts, known as heuristics-these involves 'a strategy that ignores part of the information, with the goal of making decisions more quickly, ${ }^{32}$ and includes 'develop[ing] rules of thumb and rely[ing] on ad hoc perceptions, emotions, accumulated memory, and loose associations. ${ }^{.33}$ As a result, strategies that try to give consumers all the information they need to protect themselves mostly end up providing more data than 'the "normal consumer" can bear. ${ }^{34}$ Consequently, 'few consumers take notice of [all the] information provided, ${ }^{35}$ and are therefore no better protected than if the information had not been provided in the first place.

Let us be clear though-the act of informing consumers about health risks is not inherently ineffective. Telling consumers the facts relating to the consequences of overconsumption of products such as alcohol, tobacco or unhealthy foods is an important part of NCD prevention strategy, which must be multi-sectoral in order to be effective. ${ }^{36}$ However, relying on information provision to the extent that consumer processing ability is overwhelmed, as described above, is the point at which an initially useful NCD prevention strategy such as information provision becomes a smokescreen intervention. I will now examine how MNCs have managed to, in effect, co-opt information provision strategies in order to turn them into smokescreens through an analysis of the manipulation of ideas in policy-making.

The outcome of any public policy-making process is determined by the interaction between policy interests and policy ideas. Interest groups-'collection[s] of individuals with intensely held preferences who attempt to influence government policies to benefit [their] own members ${ }^{13}$-cannot simply drive policy by 'operating according to a self-interested cost-benefit calculus'. ${ }^{38}$ Ideas or concepts are needed for policy interests to be able to articulate why their preferences should be prioritised. Hall notes that policy-makers require a 'framework of ideas and standards that specifies not only the goals of policy and the kind of instruments that can be used to attain them, but also the very nature of the problems they are meant to be addressing. ${ }^{39}$ Thus ideas are essential to the outcome of policy-making, as even 'the most cynical bureaucrats and politicians must still rationalize their actions in terms that will draw popular support. ${ }^{40}$

\footnotetext{
${ }^{28}$ P. Anderson, D. Chisholm and D.C. Fuhr, 'Effectiveness and Cost-Effectiveness of Policies and Programmes to Reduce the Harm Caused by Alcohol' (2009) 373 Lancet, 2234-2246.

${ }^{29}$ On this disconnect, see, for example, I. Ramsay, Consumer Law and Policy: Text and Materials on Regulating Consumer Markets (Hart, 2012).

${ }^{30}$ N. Malhotra, 'Information Load and Consumer Decision Making' (1982) 8(4) Journal of Consumer Research, 419-430, at 419.

${ }^{31}$ Term first coined by Herbert Simon in: H. Simon, 'A Behavioural Model of Rational Choice' (1955) 69 Quarterly Journal of Economics, 99-118, at 104.

${ }^{32}$ G. Gigerenzer and W. Gaissmaier, 'Heuristic Decision Making' (2011) 62 Annual Review of Psychology, 451-482, at 454.

33. Rachlinski, 'The Uncertain Psychological Case for Paternalism' (2003) 97 Northwestern University Law Review, 1165-1225, at 1168.

${ }^{34} \mathrm{~N}$. Reich, 'Crisis or Future of European Consumer Law?', in D. Parry, A. Nordhausen, G. Howells and C. Twigg-Flesner (eds), The Yearbook of Consumer Law 2009 (Ashgate, 2008), at 9.

${ }^{35} \mathrm{G}$. Howells, 'The Potential and Limits of Consumer Empowerment by Information' (2005) 32 Journal of Law and Society, 349-370, at 356.

${ }^{36}$ A. Alemanno and A. Garde, 'The Emergence of an EU Lifestyle Policy: The Case of Alcohol, Tobacco and Unhealthy Diets' (2013) 50 Common Market Law Review, 1745-1786.

${ }^{37}$ C. Cochran and E. Malone, Public Policy: Perspectives and Choices (Lynne Rienner, 4th edn, 2010), at 80.

${ }^{38} \mathrm{~J}$. Campbell, 'Institutional Analysis and the Role of Ideas in Political Economy' (1998) 27 Theory and Society, 377-409, at 377.

${ }^{39}$ Hall, 'Policy Paradigms, Social Learning, and the State', above, n. 5, at 281.

${ }^{40}$ Ibid., at 291.
} 
Campbell identified four characteristics of policy-making ideas. Ideas can be either 'underlying and sometimes taken-for-granted assumptions residing in the background of policy debates' ${ }^{\prime 11}$ or 'concepts and theories located in the foreground of these debates where they are explicitly articulated. ${ }^{12}$ They can also be cognitive or normative -'at the cognitive level ideas are descriptions and theoretical analyses that specify cause-and-effect relationships whereas at the normative level ideas consist of values and attitudes. ${ }^{43}$ He organises these types of ideas into a typology as follows, ranging from the highly visible and debated to the largely invisible and unquestioned: programmes (prescriptions that identify precise courses of action); frames (symbolic ideas that legitimise solutions); paradigms (operational assumptions identifying the range of useful solutions available); and public sentiments (normative assumptions constraining the range of legitimate solutions available). ${ }^{44}$

Actors with particular policy interests must utilise these ideas to make a persuasive case that their preferences for policy outcomes should be realised. This is usually achieved through the presentation of evidence that links an idea to an outcome in a sufficiently compelling way. Unfortunately, due to the complexity and breadth of the evidence that has been produced on NCDs and their causes, evidence is never entirely conclusive on most NCD issues, and as a result 'problem definition, data collection, and evaluation criteria [become] weapons used to manipulate decision outcomes towards personal ends. ${ }^{45}$ MNCs have become highly proficient at using their power to manipulate the evidence surrounding the consumption of products such as alcohol, tobacco and unhealthy foods in order to create sufficiently believable links between their preferred policy outcomes and legitimising ideas, such that their preferences-usually for information-based interventions-appear to be valid solutions to policy problems. $^{46}$

One of the reasons why MNCs have been so successful in manipulating ideas and evidence in order to secure their policy preferences is that they increase the susceptibility of policy-makers to such manipulation by playing on a host of identifiable behavioural flaws experienced by all policy-makers. The behavioural literature on policy decision-making highlights that 'decision-makers-like all other people-have a natural limited mental capacity and are therefore only able to cope within these limits and with a limited volume of information. ${ }^{47}$ Furthermore, policy decision-makers 'do not have perfect information about resulting consequences upon which to determine the best alternative [and] [a]s a consequence, there will always be uncertainty and risk about the eventual impacts of decisions taken, which means that a fully rational decision may eventually lead to an undesired effect. ${ }^{48}$ Therefore, a subtle exercise of power or influence by MNCs in the right place may prompt the engagement of such strategies in a way that makes policy-makers more susceptible to the suggestions of MNCs-a further manipulation tactic at which MNCs have unsurprisingly also become adept.

Thus, if MNCs wish to promote programmatic ideas of information provision as the most efficient method of protecting consumers, they will point out to policy-makers that information [provision] seems to offer a win-win solution. Consumers are given the means to protect themselves and drive up standards, whilst business is allowed flexibility to provide the goods and services the market demands. ${ }^{49}$ This plays on the fact that often the policy-

\footnotetext{
${ }^{41}$ Campbell, 'Institutional Analysis', above, n. 38, at 384.

${ }^{42}$ lbid.

${ }^{43}$ lbid.

${ }^{44}$ Ibid., at 385.

${ }^{45}$ J. Dean and M. Sharfman, 'The Relationship between Procedural Rationality and Political Behaviour in Strategic Decision Making' (1993) 24 Decision Sciences, 1069-1083, at 1071.

${ }^{46} \mathrm{~J}$. McCambridge, B. Hawkins and C. Holden, 'Industry Use of Evidence to Influence Alcohol Policy: A Case Study of Submissions to the 2008 Scottish Government Consultation' (2013) 10 PLoS Medicine, e100143; R. Moodie, D. Stuckler, C. Monteiro, N. Sheron, B. Neal, T. Thamarangsi, P. Lincoln and S. Casswell, 'Profits and Pandemics: Prevention of Harmful Effects of Tobacco, Alcohol, and Ultra-Processed Food and Drink Industries' (2013) 381 Lancet, 670-679, at 673.

${ }^{47}$ Kørnøv and Thissen, 'Rationality in Decision- and Policy-Making', above, n. 2, at 193.

${ }^{48}$ Ibid.

${ }^{49}$ Howells, 'Consumer Empowerment by Information', above, n. 33, at 350.
} 
making process is 'perceived in terms of winners and losers. ${ }^{50}$ Ideas for policy action that appear to lead to only winners will be seen as superior by policy-makers who will 'deny that there are trade-offs and that there are some values which many not be served by their favoured alternative ${ }^{51}$-in other words, the natural desire to find a solution that pleases everyone. To exploit this, MNCs focus on highlighting neo-classical economic views of information provision that suggest that that mere provision of information allows consumers to protect themselves and preserve their preferences, while allowing traders to innovate and drive economic growth. ${ }^{52}$ This cements the link between information provision as a guiding idea and information provision as a serious strategy, and overpowers the conclusions of more modern studies which demonstrate the ineffectiveness of information provision in NCD prevention. ${ }^{53}$

MNCs may wish to promote the idea that consumer autonomy should be preserved, in order to steer policymaking debates towards autonomy-preserving interventions such as information provision. To do this, they will remind government policy-makers of the fact that voters are 'swayed by rhetoric, framing, and advertising, and hold incumbents accountable for events that are clearly beyond the incumbent's control, ${ }^{54}$ and therefore if a government is seen to be implementing policies that restrict individual autonomy, this will be perceived unfavourably by voters. A key factor in any policy decision is that, rather than the public good, much of the time 'politicians are motivated by their concern for re-election, office and power' ${ }^{155}$ and therefore 'politicians who face frequent re-election often pursue short-term outcomes' ${ }^{156}$ that are likely to be popular and return them to office. Thus, MNCs might highlight statistics that reinforce public approval of autonomy-preserving interventions and focus attention on philosophical discourses of autonomy. ${ }^{57}$ Policy-makers will accept this evidence far more easily than statistics that show support for potentially unpopular interventions such as restrictive marketing regulations, even if such evidence is genuine. ${ }^{58}$

Finally, MNCs may wish to promote the idea that personal responsibility is at the heart of why people develop NCDs, and that interventions should be targeted accordingly. To do so, MNCs will play on the fact that policy-makers 'often do not really know what the problem is, what to aim for, [or] how to achieve it, even less what the best way is to achieve it,', 59 and therefore their 'judgement of a situation is affected by the way it is framed. ${ }^{\prime 0}$ MNCs therefore put an immense amount of effort into framing NCD prevention in terms of personal responsibility, making sure that 'those afflicted by chronic disease are generally represented as the agents of their own misfortune, typically because they have freely chosen particular health-damaging behaviours. ${ }^{.61}$ This representation of the 'problem' has been easier for policy-makers to understand and focus their attention on than evidence revealing that the real problem is a

\footnotetext{
${ }^{50}$ Kørnøv and Thissen, 'Rationality in Decision- and Policy-Making', above, n. 2, at 196.

${ }^{51}$ C. Schwenk, 'Cognitive Simplification Processes in Strategic Decision-making' (1984) 5 Strategic Management Journal, 111-128, at 119.

${ }^{52}$ See Howells, 'Consumer Empowerment by Information', above, n. 35, at 355.

${ }^{53}$ See Anderson et al., 'Effectiveness and Cost-Effectiveness', above, n. 28.

${ }^{54}$ D. Diermeier, 'Institutionalism and the Normative Study of Politics: From Rational Choice to Behavioralism' (2015) 24 The Good Society, 15-29, at 21.

${ }^{55} \mathrm{~J}$. Christensen and V. Nielsen, 'Administrative Capacity, Structural Choice and the Creation of EU Agencies' (2010) 17(2) Journal of European Public Policy, 176-204, at 184.

${ }^{56}$ R. Geneau, D. Stuckler, S. Stachenko, M. McKee, S. Ebrahim, S. Basu, A. Chockalingham, M. Mwatsama, R. Jamal, A. Alwan and R. Beaglehole, 'Raising the Priority of Preventing Chronic Diseases: A Political Process' (2010) 376 Lancet, 1689-1698, at 1691.

${ }^{57}$ On the use of ideological discourses by the tobacco industry, see J. Cohen, N. Milio, R.G. Rozier, R. Ferrence, M.J. Ashley and A.O. Goldstein, 'Political Ideology and Tobacco Control' (2000) 9 Tobacco Control, 263-267.

${ }^{58}$ Special Eurobarometer 331, EU Citizens' Attitudes Towards Alcohol, available at http://ec.europa.eu/public_opinion/archives/ebs/ ebs_331_en.pdf (accessed 1 October 2015).

${ }^{59}$ Kørnøv and Thissen, 'Rationality in Decision- and Policy-Making', above, n. 2, at 194.

${ }^{60}$ Ibid., at 193.

${ }^{61}$ Geneau et al., 'Raising the Priority of Preventing Chronic Diseases', above, n. 56, at 1692.
} 
complex web of factors the sum of which is an environment that facilitates and encourages the excessive use of products linked to NCD causation.

To summarise the above discussion, MNCs need policy-makers to accept and rely on ideas that support their preferred policy outcomes. To make this happen, MNCs have manipulated evidence and human nature using the powerful position they have acquired in order to successfully promote the proliferation of ideas that lead to the adoption of their preferred outcomes. The result is that ideas relating to information provision, consumer autonomy and personal responsibility currently hold significant sway in the NCD policy-making process. Clearly, 'political power play and compromise-making are often more important than scientific evidence in determining the outcomes ${ }^{162}-a$ game which MNCs are currently winning, and in so doing promoting the use of ineffective information provision and personal responsibility interventions. If more effective interventions on NCD prevention are to be encouraged, this situation must change. The next section will therefore discuss how power might be wrested back from MNCs.

\section{I HOW CAN THE BALANCE OF POLICY POWER BE SHIFTED TO PRODUCE EFFECTIVE POLICY OUTPUTS?}

In the previous section I showed that, by applying the power that they have acquired through building perceptions of legitimacy, MNCs have managed to manipulate the policy-making process so that ideas centred around information provision, consumer autonomy and personal responsibility have dominated, leading to several instances of policy being made that is ineffective in addressing NCD issues.

In this section, I will argue that in order to avoid making policy that only serves private interests, different ideas are needed, and that for this to happen the power acquired by MNCs must be weakened. This argument will be made in two parts-first by identifying suitable ideas and the evidence that supports them, and second by discussing how MNC legitimacy-building practices might be countered.

\subsection{Ideas that will lead to effective policy outcomes that must be promoted}

It has long been recognised that environmental and social determinants of health, on both global and local levels, lie at the heart of why people become unhealthy, ${ }^{63}$ and there have been numerous calls in the literature for these determinants to be the focus of NCD policy. ${ }^{64} \mathrm{~A}$ particular part of that environment that is especially relevant for our purposes is the manipulation of consumer behaviors and expectations by producers and retailers. Hanson and Kysar argue that 'the presence of unyielding cognitive biases makes individual decision makers susceptible to manipulation by those able to influence the context in which decisions are made. ${ }^{165}$ They present evidence that 'market outcomes frequently will be heavily influenced, if not determined, by the ability of one actor to control the format of information. ${ }^{166}$ The interests that conduct this manipulation have furthermore been identified as 'vectors of disease $^{167}$-agents who promote or facilitate the development of NCDs through activities such as those described above.

\footnotetext{
${ }^{62}$ Kørnøv and Thissen, 'Rationality in Decision- and Policy-Making', above, n. 2, at 195.

${ }^{63} \mathrm{M}$. Marmot and R. Wilkinson, Social Determinants of Health (Oxford University Press, 2nd edn, 2005).

${ }^{64}$ See, for example, R. Beaglehole and D. Yach, 'Globalisation and the Prevention and Control of Non-Communicable Disease: The Neglected Chronic Diseases of Adults' (2003) 362 Lancet, 903-908; M. Marmot, 'Improvement of Social Environment to Improve Health' (1998) 351 Lancet, 57-60; K. Rasanathan and R Krech, 'Action on Social Determinants of Health Is Essential to Tackle Noncommunicable Diseases' (2011) 89(10) Bulletin of the World Health Organization, 775-776.

${ }^{65} \mathrm{~J}$. Hanson and Kysar, 'Taking Behaviorialism Seriously, The Problem of Market Manipulation' (1999) 74 New York University Law Review 630-749, at 635.

${ }^{66}$ lbid.

${ }^{67}$ Gilmore et al., 'Public Health, Corporations and the New Responsibility Deal', above, n. 22.
} 
Clearly, the ability to solve environmental and social determinants of health, especially ones that involve purposeful manipulation, is beyond the reach of individuals. Equally clearly then, we cannot expect policy options that focus on informing the individual, that emphasise individual autonomy, and that ask the individual to act responsibly to protect their own health to make any very significant contribution towards reducing the current burden on NCDs.

Therefore, greater focus is needed on environmental and social determinants of health. To achieve this, policymakers must revise the ideas they rely on to guide them in policy-making. In the paragraphs that follow, I will identify in greater detail why the currently dominant ideas identified above are failing to produce effective policy, and suggest alternative ideas that should be promoted and employed.

First, the programmatic idea that providing individuals with information is an effective way to allow them to protect themselves is based on a paradigm of "a "deficit model" that suggests that people lack "adequate" information to make reasoned decisions. ${ }^{168}$ This is not accurate-modern evidence shows that consumer ignorance is not a 'deficit to be remedied', ${ }^{69}$ but subsists because consumers 'deliberately choose to remain ignorant of certain information,, ${ }^{\prime 70}$ and are not in full control of how the rest of it is made available.

Intervention beyond an overload of information is needed to give consumers true protection in the marketplace. For this, policy-makers should look to more interventionist programme ideas that concentrate on the wider information environment surrounding NCDs and who controls it, rather than on how consumers should receive information.

Corporate marketing efforts heavily condition the information backdrop against which consumers engage with their products, creating not only the need for many products in the first place but also the information about how to satisfy that need. Multiple studies have shown the link between increased marketing and increased consumption. ${ }^{71}$ Given the contribution of corporate marketing efforts to wider environmental and social determinants of health, policy-making focus should be on who is entitled to control the information backdrop against which individuals make lifestyle decisions. Policy-makers should therefore subscribe to programme ideas that suggest how to critically and objectively control what information MNCs should be permitted to release into the environment. Such ideas would return control of the information backdrop to government authorities, and prevent corporations from flooding it with messages that encourage and glorify unhealthy lifestyles.

Second, the largely unquestioned background idea that consumers are inherently autonomous decision-makers is completely unsupported by evidence. It has consequently provided false direction to policy debates by suggesting that protecting autonomy-perhaps with information provision-is helpful. It does not account for the fact that 'people face constraints (both internal and external) on the capacity to pursue their own interests ... [and] personal behaviour is heavily influenced and not simply a matter of free will, ${ }^{72}$ and thus has tried to protect something that either does not exist or, as Conly has argued, 'is something that has been overvalued. ${ }^{73}$ This means that many NCD policies are not concentrating on the problems that really matter-the lack of individual autonomy and manipulation of the consumer.

Alternative ideas on how to protect individual choice are required. Assuming that consumers are vulnerable to environmental manipulation, as evidence demonstrates, would lead policy-makers to far more accurately target the true problem when it comes to individual autonomy-the decision over whether to exercise choice is often made for consumers by commercial interests long before they get to the actual exercise of choice. As Waddington notes,

\footnotetext{
${ }^{68}$ U. Felt, M.D. Bister, M. Strassnig and U. Wagner, 'Refusing the Information Paradigm: Informed Consent, Medical Research, and Patient Participation' (2009) 13 Health (London), 87-106, at 90.

${ }^{69}$ Ibid.

${ }^{70}$ lbid.

${ }^{71}$ For example, L. Smith and D. Foxcroft, 'The Effect of Alcohol Advertising, Marketing and Portrayal on Drinking Behaviour in Young People: Systematic Review of Prospective Cohort Studies' (2009) 9 BMC Public Health, 51; H. Saffer and D. Dave, 'Alcohol Consumption and Advertising Bans' (2002) 34(11) Applied Economics, 1325-1334.

${ }^{72}$ L. Gostin, Public Health Law: Power, Duty, Restraint (University of California Press, 2nd edn, 2008), at 51.

${ }^{73}$ S. Conly, Against Autonomy: Justifying Coercive Paternalism (Cambridge University Press, 2012).
} 
'all consumers can potentially find themselves in a "vulnerable" position at times, depending on the circumstances.'74 Shifting our assumptions about the nature of consumer autonomy accordingly would refocus policy efforts towards consideration of how external powers are shaping individuals' ability to exercise choice in the first place. I therefore argue that ideas relating to consumer vulnerability should gain greater prominence in policy debates.

Third, the paradigmatic idea that public health intervention should start from individuals taking greater responsibility for their own well-being has limited utility. While it is true that individuals can take some useful actions in order to improve their lifestyles, the idea that encouraging individual responsibility can resolve fundamental problems at the root of NCD issues is a creation of corporations that are desperate to shift the spotlight away from the fact that it is they who actually make a more significant contribution to these fundamental root problems. Paradigmatic ideas 'guide what problems are deemed acceptable for investigation' ${ }^{75}$-this particular paradigm is falsely leading policy-makers to assume that the consumption habits of individuals are the problem, not the corporations that sell them the products they consume.

Individuals actually possess very little power to change the context in which they interact with products that are linked to NCD causation. This power lies largely with MNCs themselves. However, the real problem is that MNCs do not on the whole exercise this power for the benefit of population health. From a corporate perspective, 'once one accepts that individuals systematically behave in nonrational ways, it follows from an economic perspective that others will exploit those tendencies for gain. ${ }^{176}$ Policy ideas revolving around personal responsibility have been a clever way of disguising this uncomfortable truth.

Adopting an approach that identifies government and corporations as those with the greatest power and ability to reduce the risk of individuals being harmed by excessive consumption of products linked to NCD development would be far more likely to lead to effective NCD policy outputs. A basic rationale for why the state holds authority to make public health law is that 'no single individual, or group of individuals, can ensure the health of the community. ${ }^{77}$ By allowing themselves to be drawn in by the personal responsibility rhetoric of MNCs, government policy-makers have to a great extent 'abdicate[d] their responsibilities for the promotion and protection of their citizens' health. ${ }^{78}$ Governments must instead come to terms with the fact that corporations are responsible for creating a consumer environment in which it is easy to make unhealthy decisions. I therefore argue that ideas relating to government and corporate responsibility should gain far greater standing in policy debates.

Having offered suggestions for ideas that should replace those that are currently dominant in policy-making, I will move on to discuss how the rise of these ideas could be promoted through targeted action to reduce the power of the MNCs in policy-making.

\section{2 | Practices to target that will shift the balance of power and how to make this process transparent and acceptable}

The root of the industry's ability to influence the outcome of NCD policy-making is the aura of social legitimacy it has been able to create for itself. If MNCs lose this social legitimacy, their policy power will be weakened, and policy ideas that better reflect the public health interest can come to the fore. I propose that concerned policy-makers and public health activists can take a two-stage approach to countering the tactics used by MNCs to build social legitimacywhich, briefly, were adopting a unified front, portraying themselves as socially acceptable; and re-framing the political

\footnotetext{
${ }^{74}$ L. Waddington, 'Vulnerable and Confused: The Protection of "Vulnerable" Consumers under EU Law' (2013) 38(6) European Law Review, 757-782, at 767.

${ }^{75} \mathrm{~J}$. Peel, Science and Risk Regulation in International Law (Cambridge University Press, 2010), at 94.

${ }^{76}$ Hanson and Kysar, 'Taking Behaviorialism Seriously', above, n. 65, at 635.

${ }^{77}$ L. Gostin, 'Public Health Law in a New Century: Part I: Law as a Tool to Advance the Community's Health', (2000) 283(21) Journal of the American Medical Association, 2837-2841, at 2838.

${ }^{78} \mathrm{~K}$. Buse and A. Waxman, 'Public-Private Health Partnerships: A Strategy for WHO' (2001) 79(8) Bulletin of the World Health Organization, 748-754, at 750.
} 
debate. First, NCD prevention advocates must also organise around a stronger and more united front that is able to challenge that put forward by the industry. Second, this front must publicise and expose the true corporate motives that lie behind MNC marketing and partnership-building strategies.

To challenge MNC power, the public health community must first re-examine itself, and how it engages with policy debates. Public health currently 'suffers from poor articulation, image, and understanding ${ }^{\text {'79 }}$-those who advocate for more effective action on NCDs are no exception. Public health advocates must begin to better understand popular concerns, and engage with these concerns through a united front, if they are to prevent MNCs from winning the political debate. As Hastings notes, public health has 'become increasingly fragmented into disciplinary silos', ${ }^{80}$ with experts in various fields of NCD prevention approaching the same problem from various perspectives and hardly talking to each other. All those who advocate for more effective action on NCD prevention, whatever their specialisation, must organise under effective leadership to communicate as one voice. As Lang and Rayner put it, 'specialists need to be noisy and to build alliances. ${ }^{81}$ If NCD prevention advocates can establish the same 'boldness of purpose' 82 that drives MNCs, the domination of private interests in a debate on the health of the public can be weakened. Consequently, the first task in weakening the policy-making power of the MNCs is for the public health community to 'regain the capacity and will to address complexity and dare to confront power'. ${ }^{83}$

Once NCD prevention advocates have established a strong common purpose and sense of identity, they must take action to expose the true motivations behind industry marketing and partnership efforts. Such work has already been taking place in academic forums, using internal industry documentation to show that underlying the desirable image projected by marketing campaigns is a far more sinister intention to recruit consumers early, exploit them, and keep them consuming. ${ }^{84}$ These efforts need to be replicated on a far larger scale and in more widely distributed media than academic journals. The message must be communicated that MNCs intentionally disguise their motives and exploit consumers to place profit generation above people's long-term health. As Oliver remarks, narratives of the sort advocated here 'are most potent in triggering policy initiatives when harmful consequences are viewed as intentional rather than accidental. ${ }^{85}$ MNCs currently assert that irresponsible use of their products by a minority of individuals causes NCDs, and portray themselves as responsible partners in preventing this-the public health community must respond with public, evidentially supported discourse that reveals the extent to which consumers are manipulated to excessively consume products linked to NCD development, and the lengths to which MNCs go to promote the partnership façade. Major advances have been made in tobacco control largely due to 'perceptions of a demon industry' ${ }^{86}$ that purposefully manipulated youngsters and concealed evidence on tobacco harm from the public. Although this imagery is perhaps too strong for less homogeneous industries such as alcohol and food, within which there are smaller entities with less irresponsible motives, a more widespread perception of multinational alcohol and food corporations as unfriendly to population health interests should be promoted. This will begin to undermine the perception of such corporations as benign entities that simply provide products that are a desirable and normal part of modern life.

\footnotetext{
${ }^{79}$ T. Lang and G. Rayner, 'Ecological Public Health: The 21st Century's Big Idea? An Essay by Tim Lang and Geof Rayner', (2012) 345 British Medical Journal, e5466.

${ }^{80}$ See Hastings, 'Why Corporate Power is a Public Health Priority', above, n. 17.

${ }^{81}$ See Lang and Rayner, 'Ecological Public Health', above, n. 79.

${ }^{82}$ See Hastings, 'Why Corporate Power is a Public Health Priority', above, n. 17.

${ }^{83}$ See Lang and Rayner, 'Ecological Public Health', above, n. 79.

${ }^{84}$ See, for example, G. Hastings, "They'll Drink Bucket Loads of the Stuff": An Analysis of Internal Alcohol Industry Advertising Documents (The Alcohol Education and Research Council, 2009); L. Bero, 'Implications of the Tobacco Industry Documents for Public Health and Policy' (2003) 24 Annual Review of Public Health, 267-288; P. Ling and S. Glantz 'Why and How the Tobacco Industry Sells Cigarettes to Young Adults: Evidence from Industry Documents' (2002) 92 American Journal of Public Health, 908-926.

${ }^{85}$ Oliver, 'The Politics of Public Health Policy', above, n. 24, at 199.

${ }^{86} \mathrm{lbid}$., at 200.
} 


\section{I HOW CAN POLICY OUTPUTS ARISING FROM THE NEW BALANCE OF POWER BE JUSTIFIED?}

So far in this paper I have analysed how MNCs acquire and exercise power in order to promote policy ideas that support their policy preferences, and in so doing weaken the effectiveness of many subsequent NCD policies. I also suggested the types of policy idea that might lead to more effective outputs, and ways in which public health advocates could target the social legitimacy generated by MNCs to promote the rise of these ideas in policy-making.

The underlying argument has been that an increase in the effectiveness of NCD policy outputs requires power to be taken away from private interests so that public interests can exercise theirs to greater effect. This is not an argument, however, for an increase in control. As has hopefully been demonstrated by the discussion above, in the case of information provision, control is already exercised over the consumer, as the terms upon which they receive information are not controlled by them, but largely by private interests. Thus, I argue for a change in who holds control, not the fact that control is exerted.

Should public health advocates be successful in weakening the social legitimacy of MNCs and thus their power to control, the result will be greater control being exerted by governments on decisions made by individuals regarding the consumption of products linked to NCD development. This will increase the amount of paternalist regulation being employed-regulation which I characterise as an exercise of government power over individuals in order to substitute the preferences of individuals for those of the government. In the sections that follow I will substantiate this conception of paternalist regulation, and offer arguments as to why increased paternalism is ethically justifiable.

\subsection{What are paternalist policies and what are the objections to them?}

Paternalism has traditionally been defined as 'interference with the liberty of another for the purposes of promoting some good or preventing some harm, for the sake of the other person. ${ }^{87}$ However, I believe that it is possible to articulate a more accurate understanding of this type of regulation. I define paternalist regulation as 'governments exercising their power over individuals in order to substitute the preferences of the individual for the preferences of the government.'

I characterise paternalism in these terms firstly because it is difficult to satisfactorily define what constitutes an interference with individual liberty-or even what 'liberty' really means-and therefore what constitutes paternalism. ${ }^{88} \mathrm{I}$ argue instead that the true common denominator of paternalist action is simply an exercise of power in one way or another over individuals. In this way, paternalism is broader than mere command-and-control regulation, because the former only involves the use of formal law-making authority to directly regulate behaviour. As was made clear at the beginning of this paper, power is the ability of an actor to influence others in accordance with their own preferences-it is more than just formal authority. Thus, command-and-control regulation is only one example of an exercise of power by the government, and thus only one example of paternalism. Another example is nudging. ${ }^{89} \mathrm{~A}$ nudge at its core consists of an exertion of power to organise the individual's choice environment such that they are likely to make the decisions that government would prefer them to make. There is no direct regulation of behaviour, but the fact that a well-designed nudge will cause individuals to act in the way in which governments would prefer means that power over them is nonetheless being exerted. Thus, the extent to which individual liberty

\footnotetext{
${ }^{87}$ M. Merry, 'Paternalism, Obesity, and Tolerable Levels of Risk' (2012) 20 Democracy and Education, 1-6, at 2.

${ }^{88}$ For an example in the literature of such debate, see J. Blumenthal-Barby, 'Choice Architecture: A Mechanism for Improving Decisions While Preserving Liberty?' in C. Coons and M. Weber (eds), Paternalism: Theory and Practice (Cambridge University Press, 2012), 178-196.

${ }^{89}$ For an overview of nudge theory, see R. Thaler and C. Sunstein, Nudge: Improving Decisions about Health, Wealth and Happiness (Yale University Press, 2008); C. Sunstein and R. Thaler, 'Libertarian Paternalism Is Not an Oxymoron' (2003) 70 The University of Chicago Law Review, 1159-1202.
} 
is compromised is less relevant to characterising paternalism than whether power has been exercised over the individual.

I further characterise paternalism in terms of preference substitution rather than promoting the good of the individual. This is because it is difficult to construct a theoretical explanation of law-making upon the assertion that governments know what "good" means for individuals. Paternalist interventions applied to the whole population can never promote the subjective good of everyone they apply to because the concept of "good" is so entirely subjective and time-sensitive. One individual may believe that abstinence from alcohol is good for them for health reasons, and at the same time another individual may believe that the psychoactive properties of alcohol are the only thing that is doing them any good if they are suffering from an addiction. ${ }^{90}$ Thus, paternalist action is not really founded on a desire to promote the good of individuals, but rather on a belief that certain courses of action will bring objective benefits to individuals. This important conceptual distinction more accurately reflects the real objectives of paternalism-and in so doing makes it easier to justify. Thus, paternalism is properly characterised by a substitution of preference whereby the government's preference is for the individual to act in a way that government believes will bring objective benefits to the individual.

As can be expected, the use of government power to substitute individual preferences for government preferences attracts several objections. There is insufficient space in this paper to highlight them all, so I shall focus on two prominent objections

The first is an ethical objection, and is that '[i]f no third party interests are directly involved, the state can hardly be permitted to declare [an individual's] philosophical convictions unsound or "sick" and prevent [them] from practising them. ${ }^{\prime 91}$ This is the well-known harm principle, first articulated by J.S. Mill. He asserted that 'the only purpose for which power can be rightfully exercised over any member of a civilised community, against his will, is to prevent harm to others. His own good, either physical or moral, is not a sufficient warrant. ${ }^{92}$ These arguments draw upon liberal assumptions that 'individuals should normally be able to determine their own good', ${ }^{93}$ and that the 'denial of selfdetermination' ${ }^{\prime 94}$ is an affront to the assumption that there is 'intrinsic value in permitting an individual to decide for [themselves] even if, objectively, [they] make the 'unhealthy' choice. ${ }^{95}$ Therefore, adherents to the harm principle object to paternalism on the basis that if the outcome of an individual's preferences would harm no one but themselves, it is ethically unjustifiable for the state to decide that such practices and the preferences underlying them are undesirable, and exercise power to substitute them for ones of their own choosing. The fact that a benefit may accrue to the individual in the process is not a sufficient reason for governments to deny individual self-determination of good.

The second objection is legal and ethical in nature, and is that paternalism constitutes a disproportionate restriction on the exercise of fundamental rights by individuals, when less restrictive measures are available. The legal notion of proportionality is enshrined in EU primary law in Article 5(4) of the Treaty on European Union, and is that legal action 'shall not exceed what is necessary to achieve the objectives of the Treaty.' This mirrors the ethical principle of least restriction which is often articulated as the idea that 'more coercive methods should be employed only when less coercive methods have failed. ${ }^{96}$ Underlying the argument from proportionality is the assumption that the balance to be struck between the various competing rights must always be struck in favour of regulation that is least

${ }^{90}$ For an excellent explanation of how addictions develop, see B. Alexander, The Globalization of Addiction: A Study in Poverty of the Spirit (Oxford University Press, 2008).

91J. Feinberg, 'Legal Paternalism' (1971) 1 Canadian Journal of Philosophy, 105-124, at 115.

${ }^{92}$ J.S. Mill, 'On Liberty', in B. Wishy (ed.), Prefaces to Liberty: Selected Writings (University Press of America, 1959).

${ }^{93}$ D. Beauchamp, 'Public Health and Individual Liberty' (1980) 1 Annual Review of Public Health, 121-136, at 126.

${ }^{94}$ S. Holm, 'Obesity Interventions and Ethics' (2007) 8(Suppl. 1) Obesity Reviews, 207-210, at 207.

${ }^{95}$ L. Gostin and K. Gostin, 'A Broader Liberty: J.S. Mill, Paternalism and the Public's Health' (2009) 123(3) Public Health, 214-221, at 215.

${ }^{96}$ R. Upshur, 'Principles for the Justification of Public Health Intervention' (2002) 93(2) Canadian Journal of Public Health, 101-103, at 102. 
restrictive. Individuals have a right to an environment that gives them the opportunity to pursue their highest attainable level of health. ${ }^{97}$ However, individuals also have rights to private life, freedom of thought, and freedom of expression, ${ }^{98}$ which the substitution of individual preferences for government preferences in lifestyle decisionmaking could endanger. Thus, the objection to paternalism is made on the basis that an exercise of government power to substitute individual preferences is restrictive of fundamental rights when other interventions exists.

Having conceptualised paternalism and outlined two prominent objections to it, the last subsection of this paper will address these objections in an effort to show that paternalistic regulation should not be seen as ethically unjustifiable on these grounds.

\subsection{Reconciling paternalist policies with the objections to them}

It should be noted at the outset that there are no black or white answers when it comes to deeply normative debates such as whether paternalist intervention is right or wrong. Therefore, in this section I aim to show only that paternalist policies may be justifiable, building on the growing body of literature that offers arguments in favour of the justifiability of paternalist action. ${ }^{99}$ To argue that paternalist policies are justified would assume a level of surety that simply cannot be assumed, and which would be insensitive to the complex nature of the debate. Below, I restrict myself to discussion on the justifiability of paternalism in response to the two objections raised above.

The first objection to paternalist regulation was raised on the basis that the state may only substitute an individual's preferences against their will in order to prevent harm to others, and that behaviour only affecting the individual conducting it should remain free from state interference. This of course entails the assumption that a purely self-regarding behaviour in fact exists. In the case of the consumption of products that are linked to the development of NCDs, it is virtually impossible to describe such behaviour as purely self-regarding.

Consumption of alcohol, tobacco and unhealthy foods often produces negative effects for third parties, known as externalities. For instance, Pope notes that smoking 'can create the added social costs of health care, reduced productivity, and increased Social Security disability payments. ${ }^{100}$ Ross colourfully illustrates the point for alcohol, noting that those who choose to drink excessively 'impose costs on [the] majority-the welfare transfers themselves, plus all our loud singing and brawling and neglected children and run-over pedestrians. ${ }^{101}$ To these we might add costs to healthcare systems, to employer productivity, to victims of (for example) alcohol-related traffic incidents and crime. When individuals develop addictions to these products, even more serious harms can be suffered by others-emotional trauma of family members, or financial burdens to friends and relatives. Thus, the harm arising from consumption of objects linked to NCD development is not purely confined to the individual consumer. As a result, one must engage in a balancing exercise to determine whether the value of individual self-determination of good is worth more than the observable non-goods suffered by those surrounding the individual. The exercise of public health law is guided by a framework of ethical principles, and this framework must be approached as a whole. In doing so, the aim is to ensure a 'balance of, as opposed to a struggle between, individual freedom and community wellbeing. ${ }^{102}$ For instance, another ethical principle that should inform the adoption of public health law is that of stewardship-the idea that 'liberal states have responsibilities to look after important needs of people both

\footnotetext{
${ }^{97}$ Article 12 of the International Covenant on Economic, Social and Cultural Rights, 3 January 1976, 993 UNTS 3; Article 35 of the European Charter of Fundamental Rights [2012] OJ C 326, 26.10.2012, 391-407.

${ }^{98}$ Articles 7, 10 and 11 of the European Charter of Fundamental Rights, above, n. 97.

${ }^{99}$ For example, Conly, Against Autonomy, above, n. 73; D. Scoccia, 'In Defense of Hard Paternalism' (2008) 27 Law and Philosophy, 351-381.

${ }^{100}$ T. Pope, 'Balancing Public Health against Individual Liberty: The Ethics of Smoking Regulations' (2000) 61 University of Pittsburgh Law Review, 419-498, at 435.

${ }^{101}$ D. Ross, 'Addictive, Impulsive and Other Counter-Normative Consumption', in V. Wells and G. Foxall (eds,), Handbook of Developments in Consumer Behaviour (Edward Elgar, 2012), at 328.

${ }^{102}$ L. Lee, 'Public Health Ethics Theory: Review and Path to Convergence' (2012) 40 Journal of Law, Medicine and Ethics, 85-98, at 86.
} 
individually and collectively. ${ }^{103}$ Consequently, if policy-makers should also have regard to ethical ideas which hold that 'the value of belonging to a society in which each person's welfare, and that of the whole community, matters to everyone, ${ }^{104}$ then if the risk of health harms to the community can be seen as more significant than the risk of denying individuals self-determination of good, there is less reason to protect such self-determination. In this circumstance, legal intervention seeking to protect communities and populations, as well as individuals, is more easily justifiable.

The second objection to paternalist regulation was raised on the basis that measures which are less intrusive upon the exercise of fundamental rights should be proved insufficient before paternalist intervention is employed. This argument assumes that priority should be given to actions that are least restrictive of individual rights. However acting in a proportionate manner does not simply mean finding the least restrictive alternative. It means finding the least restrictive alternative in light of the objectives being pursued. Thus, paternalistic action, if effective in achieving a goal which is thought to be of high value, may well be a proportionate response.

Take, for example, regulation that prohibits the placing on the market of flavoured tobacco products, contained in the recent Tobacco Products Directive. ${ }^{105}$ This could be described as paternalist: the European Union exercises power to replace the preferences of individuals to smoke flavoured tobacco products, with the preference of the EU that flavoured tobacco products should not be available, with the desired outcome being a reduction in uptake of smoking (by youth in particular) caused by characterising flavours that mask the bitter taste of tobacco. This particular policy was accepted by the Advocate General of the European Union as proportionate to the objective of protecting public health on the basis that it was 'perfectly justifiable-and in any case not manifestly disproportionate ... to give precedence to the desired high level of health protection over economic and social considerations.' ${ }^{106}$ The Advocate General drew on the precautionary principle, stating that where evidence on an issue means that there is a real but uncertain risk of harm to public health arising, 'the precautionary principle justifies the adoption of restrictive measures, provided those measures are non-discriminatory and objective.' ${ }^{107}$ She continued to state that 'against this background, it was perfectly reasonable and possibly even necessary, in accordance with the precautionary principle, to lay down strict rules on the use of characterising flavours in tobacco products, especially since under primary law a high level of health protection was to be ensured. ${ }^{108}$ This illustrates that it is possible to attach greater value to some fundamental freedoms than to others, and that in such circumstances an action that happens to be paternalistic in nature may not be too strong an action to take, if it is effective and necessary in achieving the more valued objective. Therefore, when fundamental rights and freedoms must be balanced against each other in the adoption of public health policies, the fact that paternalistic measures tend to be restrictive should not constitute a bar on their being a legally proportionate or ethically acceptable response to a problem.

\section{5 | CONCLUSION}

I have attempted to show in this paper how MNCs have managed to gain policy power, and to exert this power to influence policy-making on NCD issues to generate a number of smokescreen policies. I argued that the strategies used by the industry to build legitimacy and power should be targeted by organised and united efforts of the public health community to weaken the power of MNCs and thus put the balance of power firmly back in the hands of

\footnotetext{
${ }^{103}$ Nuffield Council on Bioethics, Public Health: Ethical Issues (Nuffield Council on Bioethics, 2007), at 25.

${ }^{104}$ T. Baldwin, R. Brownsword and H. Schmidt, 'Stewardship, Paternalism and Public Health: Further Thoughts' (2009) 2 Public Health Ethics, 113-116, at 116.

${ }^{105}$ Directive 2014/40/EU, OJ L 127/1, 29.4.2014.

${ }^{106}$ Opinion of Advocate General Kokott, delivered 23 December 2015 in Case C-358/14 Poland v. Parliament and Council, ELCl:EU: C:2015:848, para. 134.

${ }^{107}$ Ibid., para. 95.

${ }^{108}$ Ibid., para. 98.
} 
public interests. I further argued that this process would result in increased regulation that could be characterised as paternalist, but that such a development is ethically and legally justifiable.

The opinions that I have articulated here form part of a wider project of research. In order to fully demonstrate the necessity of organised and public confrontation of MNCs by the public health community, more work is necessary. Further discussion is needed of the relationship between paternalism and other ethical principles in NCD policy, such as the principles of autonomy, transparency and stewardship, and I strongly advocate research into the suitability of principles such as the harm principle-now decades old and conceived of in a different era of public health-for guiding 21st-century public health efforts. A discussion of the theoretical underpinnings of public health law, for example theories of social justice, must also play a far larger part in showing that MNCs should not be entitled to dictate the health outcomes of individuals and populations. It is my hope that this paper has made a worthwhile contribution to emerging calls for a more frank look at how and why corporations with no interest in protecting the health of the public should be given public health policy-making power.

How to cite this article: Bartlett O. Power, policy ideas and paternalism in non-communicable disease prevention. Eur Law J. 2018;24:474-489. https://doi.org/10.1111/eulj.12216 